\title{
IMPACT OF TAMS IN TUMOUR MICROENVIRONMENT AS PROGNOSTIC MARKERS IN BREAST CANCER
}

\author{
Luciana V Q Labre1, Vera A Saddi2,3,4, Aline C Batista5 , Juliana F Paes², Jessica E P Ramos ${ }^{2,3,4}$, \\ Cesar A S T Vilanova-Costa ${ }^{6}$, Erika C Aquino', Silvia H Rabelo-Santos ${ }^{1,7}$ \\ ${ }^{1}$ Instituto de Patologia Tropical e Saúde Pública - Universidade Federal de Goiás - Goiânia (GO), Brazil. \\ ${ }^{2}$ Programa de Pós-graduação em Ciências da Saúde, Universidade Federal de Goiás - Goiânia (GO), Brazil. \\ ${ }^{3}$ Laboratório de Diversidade Genética, Pontifícia Universidade Católica de Goiás - Goiânia (GO), Brazil. \\ ${ }^{4}$ Laboratorio de Oncogenética e Radiobiologia, Hospital Araújo Jorge, Associação de Combate ao Câncer em Goiás - \\ Goiânia (GO), Brazil. \\ ${ }^{5}$ Faculdade de Odontologia, Universidade Federal de Goiás - Goiânia (GO), Brazil. \\ ${ }^{6}$ Laboratório de Biologia Tumoral e transplante de Medula Óssea, Hospital Araújo Jorge, Associação de Combate ao Câncer \\ em Goiás - Goiânia (GO), Brazil. \\ ${ }^{7}$ Faculdade de Farmácia, Universidade Federal de Goiás - Goiânia (GO), Brazil.
}

The objective of this study was to relate the presence of tumor-associated macrophages (TAMs) from 82 breast cancer cases with clinico-pathological characteristics of breast cancer cases and to assess the impact of TAMs on the tumor as a possible prognostic marker. The selection of the cases was made from the search of anatomopathological records in a reference center for the treatment of cancer. We included confirmed cases of diagnosis of invasive ductal breast cancer, with clinical follow-up for five years. The laminas were subjected to immunihistochemical analysis with monoclonal antibody TAMs (CD68). In the statistical analyzes, the cases were classified according to the semi-quantitative evaluation of cell marking as low infiltration or high infiltration and according to the mean. Elevated levels of TAMs (CD68+) were significantly correlated with patient age, presence of distant metastasis, more advanced tumor staging, absence of estrogen receptors (ER) and progesterone (PR), and triple negative breast cancer (TNBC). The survival of the cases of breast cancer with larger TAM infiltrate was reduced corroborating with the other results found. The number of CD68 positive cells represented a strong independent prognostic factor. The presence of TAMs in this study served as an indicator of a worse prognosis among women with the TN phenotype. The high infiltration of TAMs significantly impacted prognostic factors relevant to cases of women with breast cancer. 